\title{
The Ronnie Gardiner Rhythm and Music Method - a feasibility study in Parkinson's disease
}

Petra Pohl, Nil Dizdar and Eva Hallert

\section{Linköping University Post Print}

\section{Tweet}

N.B.: When citing this work, cite the original article.

Original Publication:

Petra Pohl, Nil Dizdar and Eva Hallert, The Ronnie Gardiner Rhythm and Music Method - a feasibility study in Parkinson's disease, 2013, Disability and rehabilitation, (35), 26, 2197 2204.

http://dx.doi.org/10.3109/09638288.2013.774060

Copyright: Informa Healthcare http://informahealthcare.com/

Postprint available at: Linköping University Electronic Press http://urn.kb.se/resolve?urn=urn:nbn:se:liu:diva-98249 


\section{TITLE PAGE}

\section{Manuscript title}

The Ronnie Gardiner Rhythm and Music Method - a feasibility study in Parkinson's disease

\section{Authors:}

1. Petra Pohl, PhD student, RPT, Dept. of Community Medicine and Rehabilitation, Physiotherapy, Umeå University, S-901 87 Umeå, Sweden and Department of Neurology, University Hospital, Linköping, Sweden

2. Nil Dizdar Segrell, MD, PhD, Department of Neurology, University Hospital, Linköping, Sweden and Department of Clinical and Experimental Medicine, Linköping University, S-581 83 Linköping, Sweden

3. Eva Hallert, MD, PhD, RPT, Center of Medical Technology Assessment, Department of Medical and Health Sciences, Linköping University, S-581 83 Linköping, Sweden

*Correspondence to: Petra Pohl, Dept of Community Medicine and Rehabilitation, Umeå University, 90187 Umeå, Sweden. Telephone: + 46907869882

E-mail: petra.pohl@physiother.umu.se

Key words: Music Therapy, Parkinson's disease, Quality of Life, Neurological disorders 


\begin{abstract}
Purpose: The purpose of this study was to examine the feasibility of and effects from the Ronnie Gardiner Rhythm and Music (RGRM $\left.{ }^{\mathrm{TM}}\right)$ Method on motor function, cognition and quality of life in persons with Parkinson's disease.
\end{abstract}

Method: Eighteen participants with Parkinson's disease were randomized into intervention group or control group. Over 6 weeks, the intervention group attended 12 one-hour classes with RGRM ${ }^{\mathrm{TM}}$. The control group had no activity. Motor function, cognition, and quality of life were evaluated before and after the intervention. Motor function was assessed by Unified Parkinson Disease Rating Scale (UPDRS) motor part III, Timed Up-and-Go and a twodimensional motion analysis. Cognitive function was assessed by Cognitive Assessment Battery. Quality of life was assessed by Parkinson Disease Questionnaire-39 summary index.

Results: The intervention group improved significantly over time in motor function (UPDRS motor part III and median time on motion analysis), cognitive function (verbal memory, language, and executive function and attention), and quality of life. There was no significant difference between the groups in any of the outcomes.

Conclusions: Twelve classes with RGRM ${ }^{\mathrm{TM}}$ improved motor function, cognition, and quality of life in 12 participants with Parkinson's disease. This is the first report of the use of RGRM $^{\mathrm{TM}}$ in rehabilitation. 


\section{Introduction}

Music as therapy has been used for many years as an alternative method in patients with Parkinson's disease (PD) [1-3]. It has been proven useful in neurological rehabilitation [4-7]. Recent research has shown that listening to and performing music may affect many different brain structures involving cognition, sensorimotor areas and even emotional processes [8-10]. Music therapy can be active, where participants sing, make movements and play instruments, or passive, with participants listening to music $[1,2]$. The focus of active music therapy lies on functional skill redevelopment [5] and engages sensory processes, attention, memoryrelated processes, perception-action related mediation (mirror neuron system activity), multisensory integration and social cognition [9]. It has also been suggested that active music therapy may stabilize the disturbed sense of rhythm in patients with PD $[2,11]$.

PD is a progressive disease associated with neurodegeneration of the dopaminergic cells in the basal ganglia, characterized by progressive motor impairment, cognitive impairment and depression [12]. The management includes medical treatment, physiotherapy and in some cases surgical treatment, i.e. deep brain stimulation [12-14]. Physiotherapy aims at increasing functional ability and minimizing secondary complications by movement rehabilitation $[15$, 16]. A common and effective strategy to improve gait performance and mobility is to apply external (auditory) cueing techniques [17]. Thaut and colleagues showed that rhythmic auditory stimulation during a gait-training programme for patients with PD significantly improved gait velocity, stride length, and step cadence compared to a control group [18]. Rhythm is a powerful stimulus for activity and several studies have shown that therapies including rhythm are beneficial for patients with PD [6, 19-22]. In addition, it has been suggested that music may affect the reward system of the brain [23]. 
The novel music-based movement therapy Ronnie Gardiner Rhythm and Music (RGRM ${ }^{\mathrm{TM}}$ ) Method was developed in 1993, and has been implemented in rehabilitation and health care centres in Sweden. The intervention focuses on exercises that challenge cognition and sensorimotor control to improve mobility and coordination in patients with neurological deficits through the use of rhythm and music. The recommended amount of training is twice weekly for at least 12 weeks. Many persons with PD avoid participation in rehabilitation therapies due to fear of falling, anxiety, lack of motivation or pain [24]. The RGRMTM Method is considered enjoyable, motivating and engaging and may help in increasing motivation for rehabilitation. It is a complement to other rehabilitation methods and may be used by physiotherapists as well as occupational or speech therapists. Physical abilities, like weight shifting, rising from a chair, postural stability with secondary tasks and sequences of action as well as kinaesthetic awareness are practiced through rhythmic, reciprocal movements, all of which are suggested by King and colleagues [25]. The method is mentioned in the Swedish National Guidelines for Stroke [26] and there are a few small theses that show positive effects on mobility, speech fluency and quality of life in patients with stroke. This is the first study to evaluate the method in persons with PD, although the method is frequently being used for individuals with PD.

The purpose of this study was to examine the feasibility of and effects from the RGRMTM Method on motor function, cognition and quality of life in persons with Parkinson's disease. 


\section{Methods}

\section{Participants and study design}

Participants were recruited from the Parkinson's Society in the Swedish county of Ostergotland. A maximum of 30 persons was initially set with the intention to allocate them into equally large groups. Interested potential participants were screened to determine if they met the following inclusion criteria: (1) diagnosis of PD; (2) any duration of PD; (3) any PD therapy or treatment, but stable; (4) able to get down in a squatting position and to walk at least $10 \mathrm{~m}$ without support; (5) correctable auditory and visual capability; and (6) able to access transportation to and from research sessions. Exclusion criteria were (1) secondary or atypical PD; (2) colour blindness; (3) severe depression; (4) participating in any other ongoing study; or (5) having $\geq 3$ points per question in part I, in question number 13-15 in part II and in question number 24-30 in part III of the Unified Parkinson Disease Rating Scale, UPDRS [27]. The study protocol was approved by the local Ethical Review Board and all participants gave written informed consent to participate.

\section{Study design}

A small-scale, randomized, single-blinded, control design with pre- and post-test evaluation was employed for this feasibility study. A pre-test evaluation including neurological examination was done two weeks prior to the intervention and post-tests were done two weeks after intervention. Because of fewer eligible participants than expected, and because of expected larger statistical variations in the intervention group, it was decided to randomize the participants into different sized groups: intervention group $(n=12)$ and control group $(n=6)$. An independent source used a computer-based program for randomization process. All 
assessments were done by the main author and a PD nurse during the "on phase" of medication and neurological examination was performed by a neurologist. No change in medication was allowed and no new activities were permitted during the intervention period. Participants in the control group were offered to participate in a separate session of training with the RGRM ${ }^{\mathrm{TM}}$ Method, once the intervention period was over. The participants in the intervention group had to complete at least $70 \%$ of the sessions in order to be included in the data analysis.

\section{Outcome measures}

The UPDRS total [27, 28], Hoehn \& Yahr stages [29], and Schwab \& England scale [30] were used as demographic variables. Ten selected measures were used evaluating motor function, cognition and quality of life.

\section{Motor function}

Three tests were chosen: UPDRS motor score, Timed-Up-and-Go [31], and a computerbased, two-dimensional motion analysis system based on the Posturo-Locomotion-Manual (PLM) method [32]. The PLM method consists of seven spherical markers (4 cm diameter) covered with light-reflective tape are placed on standardized locations on the most affected side of the body, the side of the head, shoulder, arm, hip and on both legs. The person is asked to move a small (500 g) object, also covered with reflective tape, repeatedly ( $3 \times 10$ sets) as quickly as possible from a marked starting place on the floor, to a stand located at chin level, $1.5 \mathrm{~m}$ in front of the starting place. Thus, the person is forced to bend when picking up the handle and rise to regain postural stability (figure 1). An opto-electronic measurement system was used to record movement performance (PDMonitor, QbTech AB, 
Gothenburg, Sweden). The markers' position in two-dimensional space was recorded every 20 milli-seconds by the opto-electronic system using infrared flashlight. The test measures postural stability (Posture), walking (Locomotion) and targeted arm movements (Manual), and provides a good overview of the motor symptoms [32].

Insert figure 1 about here.

\section{Cognition}

Cognitive ability was evaluated with the Cognitive Assessment battery (CAB) [33]. CAB provides a cognitive investigation, more thorough than traditional tests such as Mini Mental State Examination, but less time-consuming than neuropsychological examinations [33]. In total, $\mathrm{CAB}$ comprises five different domains; learning and episodic memory, speed and attention, visuo-spatial functions, language, and executive functions. In order to assess feasibility and evaluate cognitive changes practiced by the RGRM ${ }^{\mathrm{TM}}$ Method, a selection of 6 tests within all domains were analyzed in this study: the Text recall test, the Symbol Digit Modalities Test (SDMT), Clox and Cube, Naming 30 items, Stroop Color-Word Test and the Parallel Serial Mental Operations, PaSMO (table 1).

Insert table 1 about here.

\section{Quality of Life}

The Swedish version [34] of the Parkinson Disease Questionnaire-39 summary index [35] (PDQ-39) was used. 


\section{Intervention}

The intervention comprised 12 supervised one-hour sessions over a period of 6 weeks (twice weekly). During the sessions, participants followed the, for this method unique, "notes" in the shape of specific symbols accompanied by sound enunciations and rhythmic movements such as foot stomping or hand clapping to the sound of rhythmical music. The symbols are shaped like a hand or a foot, or a combination of hand and foot (18 in total) and are projected as large symbols against the wall. The colour red symbolizes the left side of the body and the colour blue symbolizes the right side of the body. The sound enunciations associated with the symbols are based on the sounds from a drum kit. For instance, if the "note" shaped as a blue hand is projected; this corresponds to tapping the right thigh and simultaneously pronouncing the word "TING" (sound of cymbal). Each beat of the music is accompanied by one of the "notes". Specific schedules with notes are followed beat by beat and the participants must stay focused all the time in order not to lose track of where on the schedule they are. The notes can be used in various ways, e.g. in black and white or with letters only (for example TING or TOOM without symbols) to increase the level of difficulty of the exercises. The schedules can be followed forwards, backwards or from the bottom to the top in order to make the exercises more difficult. Countless variations are possible and the combination of the "notes" may frequently be changed to avoid habituation. The certified RGRM"TM practitioner wears a special shirt where the back is coloured blue on the right side and red on the left side, aiming to reinforce the impression of left and right side of the body. 


\section{Data analysis}

Data are presented as mean (SD) or median (IQR). The Mann-Whitney U-test was used to test differences between groups and $\chi^{2}$ or Fisher's exact test was used for differences in proportions. Comparisons within groups were analyzed using Wilcoxon signed rank test. No adjustments for multiple comparisons were made. The level of significance was set at 5\%. All analysis was performed using SPSS 17.0 (SPSS Inc., Chicago, IL, USA). A power analysis based on the results from PLM using independent samples t-test was performed with the “Russ Lenth's power and sample size page" [36].

\section{Results}

Eighteen participants, 8 men and 10 women, met the eligibility criteria and were recruited for the study. The mean age was $68.2 \pm 5.1$ years, mean disease duration $8.8 \pm 3.8$ years, mean stage on Hoehn \& Yahr was $2.4 \pm 0.7$, mean Schwab \& England was $84.4 \pm 7.0 \%$, and mean score on UPDRS total was $41.8 \pm 11.4$ points. Except for a small difference in Symbol Digit Modalities Test, there were no significant differences between the two groups after randomization (table 2). Insert table 2 about here. Two participants were lost from the control group. One participant withdrew due to medical complications unrelated to PD, and one was excluded after altered medication during the intervention period. Two participants missed two sessions each and 10 participants completed all 12 intervention sessions. No adverse events were reported. The final analyses were based on the 16 participants who completed the intervention period (figure 2).

Insert figure 2 about here. 


\section{Motor function}

Significant improvements from pre-test to post-test were found in UPDRS motor score part III $(\mathrm{p}=0.003)$, and in PLM movement time $(\mathrm{p}=0.006)$ in the intervention group, whereas no significant changes were seen in the control group (table 3). No significant differences were found in the Timed-up-and-Go test.

\section{Insert table 3 about here.}

\section{Cognitive function}

Significant improvements from pre-test to post-test were found in three cognitive tests in the intervention group; verbal memory (Text recall test, $\mathrm{p}=0.036$ ), language (Naming 30 items, $p=0.033$ ), and executive function and attention (Stroop Color-Word test, $p=0.007$ ), but no significant improvements in the control group (table 3 ).

\section{Quality of Life}

The perceived quality of life improved in the intervention group, but not in the control group (table 3).

\section{Power calculation}

A power calculation was performed based on results of the PLM method with the assumption of a true difference of means of 0.20 seconds. The level of power was set to at least $80 \%$ and level of significance to $5 \%$. The standard deviation was set to 0.31 based on results from the intervention group. With the assumption of equally large groups, and with an expected drop- 
out of $20 \%$, a number of 90 participants should be required in a future study with the same design.

\section{Discussion}

To our knowledge this is the first pilot study to evaluate the feasibility and effectiveness of RGRMTM $^{\mathrm{TM}}$ Method in persons with PD. The RGRMTM Method proved to be a feasible intervention, in that all participants completed at least $70 \%$ of the intervention sessions.

The authors hypothesized that training with the RGRM ${ }^{\mathrm{TM}}$ Method may improve motor function and some intellectual functions which are typically impaired in PD, as well as improving quality of life. This study has demonstrated that a 6-week RGRM ${ }^{\mathrm{TM}}$ programme can produce improvements in motor and cognitive function as well as quality of life. Our findings are in agreement with previous studies, where rhythmic elements have been used in patients with PD [2, 18, 20-22]. Although not all our findings reached statistical significance, the results may be clinically relevant.

It can be argued that a median improvement of 0.20 seconds in movement time of the PLM test (max $-1.08, \min +0.20)$ is of small clinical relevance. However, this is an improvement of nearly $10 \%$, and since the UPDRS motor score also showed significant improvements, 0.20 seconds may in fact be quite important. There is no reason to believe that there was a learning effect involved, as the test only took five minutes to perform and there were almost 2 months between the testing dates. 
Cognitive impairments may be more difficult to cope with than motor impairments in Parkinson's disease [37], and it is therefore considered important to improve impairments such as executive functions and memory. The intervention group improved significantly in three out of six tests. The RGRM ${ }^{\mathrm{TM}}$ Method aims at stimulating mental flexibility, increasing the ability to concentrate and achieving a general alertness. These components are quite similar to, for example, the Stroop Color-Word test. It must, however, be taken into consideration, that 12 out of 16 participants performed within normal variations on all tests in the $\mathrm{CAB}$, including the Stroop Color-Word test. The improvement in the Text recall test may be a result of a general alertness due to the training itself. The test is however rather superficial and future studies would gain upon including more thorough memory tests.

The intervention group also reported a significantly improved quality of life after the 6 week period. It has previously been reported that PD patients sometimes avoid participation in rehabilitation programmes due to lack of motivation or anxiety [24]. Music is known to elicit emotional responses, as moving to music activates endorphin-related brain's pleasure circuits [23], and since the RGRM ${ }^{\mathrm{TM}}$ Method offers social interaction, as well as body awareness and joy of movement through the deliberate use of music, it is possible that this method may enhance the motivation to participate also in other rehabilitation programmes.

The reasons for the non-significant differences between the intervention and control groups in any of the measured outcomes may be several. First, the small sample sizes may have given non-significant results, since there were only four participants in the control group and very small changes may substantially affect the results. Allocating participants into two equally large groups would probably have been a better option. Secondly, the intervention period was only 6 weeks, instead of recommended 12 weeks. Thirdly, it can be argued that the intensity 
of the training was too low, as all patients were beginners. It has been described that persons with PD often present substantial problems when starting a training period due to poor coordination, balance and strength. Thus, exercise with PD patients usually must start at lower levels of intensity in order to build self-confidence and give adherence to the programme participation. In addition, all participants were members of the Parkinson Disease Society. Most of these persons were curious about this method and given the opportunity, they volunteered to participate, which makes it hard to generalize the results on all persons with PD. The fact that they had a reason to get up, get dressed, travel, spend time in the company with others (social interaction) etc, may also have affected the intervention group in a positive direction (Hawthorne effect [38]). Indeed, the physical activity per se, may give pleasure, increased social interaction, experience of one's body and increased self-confidence. However, this alone does not explain why they improved on the motor function assessments as well as three of the cognitive tests and quality of life.

Some additional limits may be mentioned: the subjects were classified as having mild to moderate PD according to the Hoehn \& Yahr scale, making the results not applicable in patients more severely affected by PD. Furthermore, no follow-ups were performed to see if improvements were maintained.

To conclude, despite the small sample sizes and possible significant changes by chance, the present study suggests that the RGRM ${ }^{\mathrm{TM}}$ Method may be a useful and appropriate treatment alongside with traditional rehabilitation for patients with Parkinson's disease. Further studies are needed and power analysis based on results of the present study, assuming a $20 \%$ drop out, 90 participants in future studies for a period of 12 weeks. 


\section{Acknowledgements}

The authors would like to thank all participants who took part in this study, Marie Fredriksen for leading the intervention group, Lars Valter for statistical advice, Mats Eklund for providing the opto-electronic equipment, Arto Nordlund and Pfizer for providing us with $\mathrm{CAB}$, and Ing-Mari Ruuth Knutsson for helping with assessments. The study was financially supported by Ostergotland County Council and Department of Neurology, Linköping University Hospital.

\section{Declaration of Interest}

The authors report no declarations of interest. 


\section{References}

[1] Pacchetti C, Aglieri R, Mancini F Martignoni E, Nappi G. Active music therapy and Parkinson's disease: methods. Funct Neurol 1998;13:57-67.

[2] Pacchetti C, Mancini F, Aglieri R, Fundarò C, Martignoni E, Nappi G. Active music therapy in Parkinson's disease: an integrative method for motor and emotional rehabilitation. Psychosom Med 2000;62:386-93.

[3] de Dreu MJ, van der Wilk AS, Poppe E, Kwakkel G, van Wegen EE. Rehabilitation, exercise therapy and music in patients with Parkinson's disease: a meta-analysis of the effects of music-based movement therapy on walking ability, balance and quality of life. Parkinsonism Relat Disord 2012;18 Suppl 1:S114-9.

[4] Aldrigde D, editor. Music Therapy and Neurological Rehabilitation: Performing Health. London: Jessica Kingsley Publishers 2005.

[5] Baker F, Tamplin J. Therapy Methods in Neurorehabilitation - A Clinicians Manual. London: Jessica Kingsley Publishers 2006.

[6] Thaut MH, Gardiner JC, Holmberg D, Horwizt J, Kent L, Andrews G. Neurologic music therapy improves executive function and emotional adjustment in traumatic brain injury rehabilitation. Ann N Y Acad Sci 2009;1169:406-16.

[7] Bradt J, Magee WL, Dileo C, Wheeler BL, McGilloway E. Music therapy for acquired brain injury. Cochrane Database Syst Rev 2010:CD006787.

[8] Zatorre RJ, Chen JL, Penhune VB. When the brain plays music: auditory-motor interactions in music perception and production. Nature Reviews Neuroscience 2007;8:54758.

[9] Koelsch S. A neuroscientific perspective on music therapy. Ann N Y Acad Sci 2009;1169:374-84. 
[10] Aldridge D, editor. Gesture and Dialogue: Music Therapy as Praxis Aesthetic and Embodied Hermeneutic. London: Jessica Kingsley Publishers 2005.

[11] Yahalom G, Simon ES, Thorne R, Peretz C, Giladi N. Hand rhythmic tapping and timing in Parkinson's disease. Parkinsonism Relat Disord 2004;10:143-8.

[12] Yanagisawa N. Natural history of Parkinson's Disease: From dopamine to multiple system involvement. Parkinsonism Relat Disord 2006:S40-S6.

[13] Park A, Stacy M. Non-motor symptoms in Parkinson's disease. J Neurol 2009;256 Suppl 3:293-8.

[14] Weaver FM, Stern MB, Follett K. Deep-brain stimulation in Parkinson's disease. Lancet Neurol 2006;5:900-1.

[15] Deane KH, Jones D, Playford ED, Ben-Shlomo Y, Clarke CE. Physiotherapy for patients with Parkinson's Disease: a comparison of techniques. Cochrane Database Syst Rev 2001:CD002817.

[16] Keus SH, Bloem BR, Hendriks EJ, Bredero-Cohen AB, Munneke M, Practice Recommendations Development Group. Evidence-based analysis of physical therapy in Parkinson's disease with recommendations for practice and research. Mov Disord 2007;22:451-60; quiz 600.

[17] Lim I, van Wegen E, de Goede C, Deutekom M, Nieuwboer A, Willems A. Effects of external rhythmical cueing on gait in patients with Parkinson's disease: a systematic review. Clin Rehabil 2005;19:695-713.

[18] Thaut MH, McIntosh GC, Rice RR, Miller RA, Rathbun J, Brault JM. Rhythmic auditory stimulation in gait training for Parkinson's disease patients. Mov Disord 1996;11:193-200.

[19] Enzensberger W, Oberländer U, Stecker K. Metronome therapy in patients with Parkinson disease. Nervenarzt 1997;68:972-7. 
[20] Arias P, Cudeiro J. Effect of rhythmic auditory stimulation on gait in Parkinsonian patients with and without freezing of gait. PLoS One 2010;5:e9675.

[21] Brown LA, de Bruin N, Doan JB, Suchowersky O, Hu B. Novel challenges to gait in Parkinson's disease: the effect of concurrent music in single- and dual-task contexts. Arch Phys Med Rehabil 2009;90:1578-83.

[22] de Bruin N, Doan JB, Turnbull G, Suchowersky O, Bonfield S, Hu B. Walking with music is a safe and viable tool for gait training in Parkinson's disease: the effect of a 13-week feasibility study on single and dual task walking. Parkinson's Disease 2010;2010:483530.

[23] Blood AJ, Zatorre RJ. Intensely pleasurable responses to music correlate with activity in brain regions implicated in reward and emotion. Proc Natl Acad Sci U S A 2001;98:1181823.

[24] Paul S, Ramsey D. Music therapy in physical medicine and rehabilitation. Australian Occupational Therapy Journal 2000:111-8.

[25] King LA, Horak FB. Delaying mobility disability in people with Parkinson disease using a sensorimotor agility exercise program. Phys Ther 2009;89:384-93.

26. The Swedish National Guidelines for Stroke 2005. In: Board SS, edition 2006.

[27] Movement Disorder Society Task Force on Rating Scales for Parkinson's Disease. The Unified Parkinson's Disease Rating Scale (UPDRS): status and recommendations. Mov Disord 2003;18:738-50.

[28] Siderowf A, McDermott M, Kieburtz K, Blindauer K, Plumb S, Shoulson I. Test-retest reliability of the unified Parkinson's disease rating scale in patients with early Parkinson's disease: results from a multicenter clinical trial. Mov Disord 2002;17:758-63.

[29] Hoehn MM, Yahr MD. Parkinsonism: onset, progression and mortality. Neurology 1967;17:427-42. 
[30] Schwab J, England A. Projection techniques for evaluating surgery in Parkinson's disease. Third Symposium on Parkinson's Disease 1968:122-57.

[31] Morris S, Morris ME, Iansek R. Reliability of measurements obtained with the Timed "Up \& Go" test in people with Parkinson disease. Phys Ther 2001;81:810-8.

[32] Johnels B, Ingvarsson PE, Steg G, Olsson T. The Posturo-Locomotion-Manual Test. A simple method for the characterization of neurological movement disturbances. Adv Neurol 2001;87:91-100.

[33] Nordlund A, Påhlsson L, Holmberg C, Lind K, Wallin A. The Cognitive Assessment Battery (CAB): a rapid test of cognitive domains. Int Psychogeriatr 2011:1-8.

[34] Hagell P. Feasibility and linguistic validity of the Swedish version of the PDQ-39. Expert Rev Pharmacoecon Outcomes Res 2005;5:131-6.

[35] Jenkinson C, Fitzpatrick R, Peto V, Greenhall R, Hyman N. The Parkinson's Disease Questionnaire (PDQ-39): development and validation of a Parkinson's disease summary index score. Age Ageing 1997;26:353-7.

[36] Lenth RV. Java Applets for Power and Sample Size. http://www.stat.uiowa.edu/ rlenth/Power 2006-9:Computer software.

[37] Weaver F, Stern M, Follett K. Deep-brain stimulation in Parkinson's disease. Lancet Neurol 2006;5:900-1.

[38] Benedetti F, Carlino E, Pollo A. How placebos change the patient's brain. Neuropsychopharmacology 2011;36:339-54. 
TABLE 1. Baseline characteristics of intervention group and control group, median and inter-quartile range (q1; q3) and p-values for difference.

\begin{tabular}{|c|c|c|c|c|c|}
\hline \multirow[b]{2}{*}{ Outcome measure } & \multicolumn{2}{|c|}{ Intervention group } & \multicolumn{2}{|c|}{ Control group } & \multirow[b]{2}{*}{$P$-value } \\
\hline & & $(\mathrm{n}=12)$ & & $(\mathrm{n}=6)$ & \\
\hline \multicolumn{6}{|l|}{ Motor function } \\
\hline Timed-Up-and-Go (sec) & 10.5 & $(8.3 ; 13.8)$ & 10.0 & $(8.3 ; 11.8)$ & 0.67 \\
\hline PLM movement time (sec) & 2.07 & $(1.78 ; 2.81)$ & 2.20 & $(1.88 ; 2.95)$ & 0.54 \\
\hline UPDRS motor score (0-56 p) & 19.0 & $(15.3 ; 25.0)$ & 17.5 & $(8.5 ; 26.5)$ & 0.62 \\
\hline \multicolumn{6}{|l|}{ Cognitive function } \\
\hline Text recall test $(0-21 \mathrm{p})$ & 4.0 & $(3.0 ; 6.8)$ & 3.5 & $(0.8 ; 6.3)$ & 0.54 \\
\hline SDMT (0-110) & 36.0 & $(29.0 ; 41.5)$ & 20.5 & $(15.0 ; 29.8)$ & 0.03 \\
\hline Clox and Cube (0-12) & 11.5 & $(9.3 ; 12.0)$ & 10.5 & $(9.3 ; 11.8)$ & 0.61 \\
\hline Naming 30 items $(0-30)$ & 28.0 & $(27.0 ; 28.8)$ & 26.0 & $(21.5 ; 29.0)$ & 0.22 \\
\hline Stroop Color-Word test (sec) & 28.0 & $(22.0 ; 41.5)$ & 30.5 & $(24.5 ; 54.5)$ & 0.59 \\
\hline PaSMO (sec) & 82.5 & $(65.5 ; 87.0)$ & 122.5 & $(75.3 ; 277.8)$ & 0.23 \\
\hline \multicolumn{6}{|l|}{ Quality of Life } \\
\hline PDQ-39 (0-100 p) & 27.8 & $(16.7 ; 41.4)$ & 29.8 & $(22.9 ; 38.7)$ & 0.72 \\
\hline
\end{tabular}

UPDRS: Unified Parkinson's Disease Rating scale; PLM: Posturo-Locomotion-Manual; SDMT: Symbol Digit Modalities Test; PaSMO, Parallel Serial Mental Operations; PDQ-39: Parkinson's Disease Questionnaire-39 summery index. 
TABLE 2. Changes from baseline to follow-up at week 6 on the outcome measures presented as median and inter-quartile (q1; $\mathrm{q} 3$ ) and pvalues for differences.

\begin{tabular}{|c|c|c|c|c|c|c|}
\hline \multirow[b]{2}{*}{ Outcome measure } & \multirow{2}{*}{\multicolumn{2}{|c|}{ Baseline }} & \multicolumn{2}{|l|}{ Baseline } & \multirow{2}{*}{$\begin{array}{l}\text { Between groups } \\
\text { comparison } \\
P \text {-value }\end{array}$} & \multirow{2}{*}{$\begin{array}{l}\text { Within groups } \\
\text { comparison } \\
P \text {-value }\end{array}$} \\
\hline & & & $P$-value & Difference baseline/6 weeks & & \\
\hline \multicolumn{7}{|l|}{ Motor function } \\
\hline Timed-Up-and-Go test (secs) & & & 0.67 & & 0.33 & \\
\hline Intervention group & 10.5 & $(8.3 ; 13.8)$ & & $-0.5 \quad(-2.0 ;+1.0)$ & & 0.163 \\
\hline Control group & 10.0 & $(8.3 ; 11.8)$ & & $+1.0(-2.3 ;+2.0)$ & & 1.000 \\
\hline PLM movement time (secs) & & & 0.54 & & 0.11 & \\
\hline Intervention group & 2.07 & $(1.78 ; 2.81)$ & & $-0.20(-0.34 ;-0.03)$ & & 0.006 \\
\hline Control group & 2.07 & $(1.78 ; 2.81)$ & & $+0.03(-0.24 ;+0.16)$ & & 0.715 \\
\hline UPDRS motor score (0-56 p) & & & 0.62 & & 0.47 & \\
\hline Intervention group & 19.0 & $(15.3 ; 25.0)$ & & $-4.5 \quad(-8.8 ;-3.3)$ & & 0.003 \\
\hline Control group & 17.5 & $(8.5 ; 26.5)$ & & $-8.5 \quad(-14.0 ; 0.0)$ & & 0.144 \\
\hline \multicolumn{7}{|l|}{ Cognitive function } \\
\hline Text recall test $(0-21 \mathrm{p})$ & & & 0.54 & & 0.63 & \\
\hline Intervention group & 4.0 & $(3.0 ; 6.8)$ & & $+3.5 \quad(-1.5 ;+4.8)$ & & 0.036 \\
\hline Control group & 3.5 & $(0.8 ; 6.3)$ & & $+2.3 \quad(+1.3 ;+2.9)$ & & 0.068 \\
\hline Symbol Digit Mod. Test (0-110) & & & 0.03 & & 0.18 & \\
\hline Intervention group & 36.0 & $(29.0 ; 41.5)$ & & $+1.5 \quad(-4.0 ;+2.8)$ & & 0.753 \\
\hline Control group & 20.5 & $(15.0 ; 29.8)$ & & $+3.5 \quad(+3.5 ;+12.3)$ & & 0.144 \\
\hline Clox and Cube (0-12) & & & 0.61 & & 0.21 & \\
\hline Intervention group & 11.5 & $(9.3 ; 12.0)$ & & $\pm 0.0 \quad(-0.8 ;+1.8)$ & & 0.287 \\
\hline Control group & 10.5 & $(9.3 ; 11.8)$ & & $-0.5 \quad(-1.0 ; 0.0)$ & & 0.157 \\
\hline Naming 30 items (0-30) & & & 0.22 & & 1.00 & \\
\hline Intervention group & 28.0 & $(27.0 ; 28.8)$ & & $+0.5 \quad(0.0 ;+2.0)$ & & 0.033 \\
\hline Control group & 26.0 & $(21.5 ; 29.0)$ & & $+1.0 \quad(0.0 ;+2.0)$ & & 0.157 \\
\hline Stroop Color-Word test (sec) & & & 0.59 & & 0.54 & \\
\hline Intervention group & 28.0 & $(22.0 ; 41.5)$ & & $-2.0 \quad(-8.0 ;-0.3)$ & & 0.007 \\
\hline Control group & 30.5 & $(24.5 ; 54.5)$ & & $-0.5 \quad(-16.5 ;+2.8)$ & & 0.581 \\
\hline PaSMO (sec) & & & 0.23 & & 0.13 & \\
\hline Intervention group & 82.5 & $(65.5 ; 87.0)$ & & $-6.5 \quad(-17.0 ;+1.0)$ & & 0.054 \\
\hline Control group & 122.5 & $5(75.3 ; 277.8)$ & & $-22.0(-24.0 ;-6.5)$ & & 0.066 \\
\hline
\end{tabular}

Quality of Life 


$\begin{array}{llllll}\text { Intervention group } & 27.8 & (16.7 ; 41.4) & -3.6(-6.8 ;+0.6) & 0.031 \\ \text { Control group } & 29.8 & (22.9 ; 38.7) & -7.3(-11.9 ;+12.8) & 0.715\end{array}$

PLM, Posturo-Locomotion-Manual-test; SDMT, Symbol Digit Modalities Test; PaSMO, Parallel Serial Mental Operations.

NB: A minus sign on the PLM, UPDRS, Timed-Up-and-Go, Stroop Color-Word, PaSMO and PDQ-39 equals improvement; a plus sign on the Text recall test, SDMT, Clox and Cube and the Naming test equals improvement.

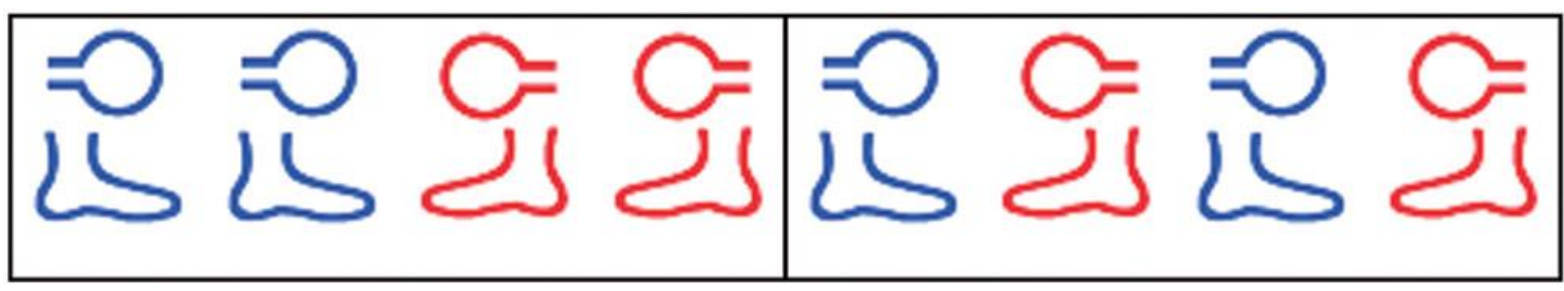

Figure 1. An example of the symbols ("notes") of the RGRM Method. A blue hand and a blue foot (pointing in the right direction) are accompanied

by the tapping on the right thigh and stomping the right foot on the floor and at the same time pronounce the word "TOOM". The figure shows 2 out of

18 symblos. Reprinted with kind permission from Ronnie Gardiner.
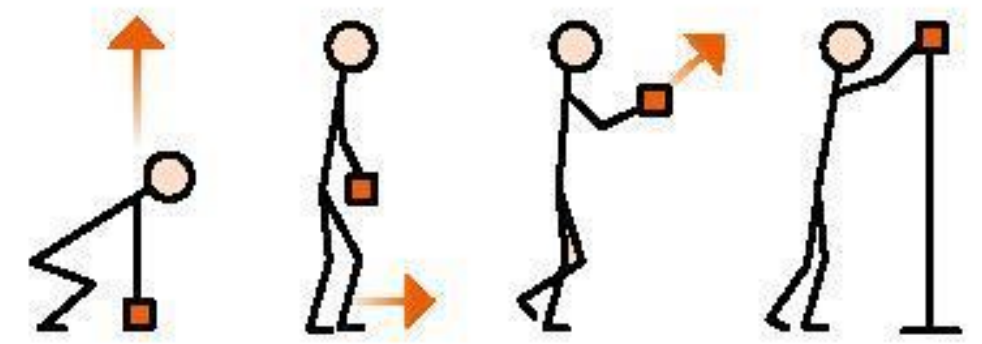

\section{Postural (P) Locomotion (L) Manual (M)}

Figure 2. PLM methods' different parts; posture (rising from a squatting position), locomotion (walking forward), manual (targeted arm movement). 


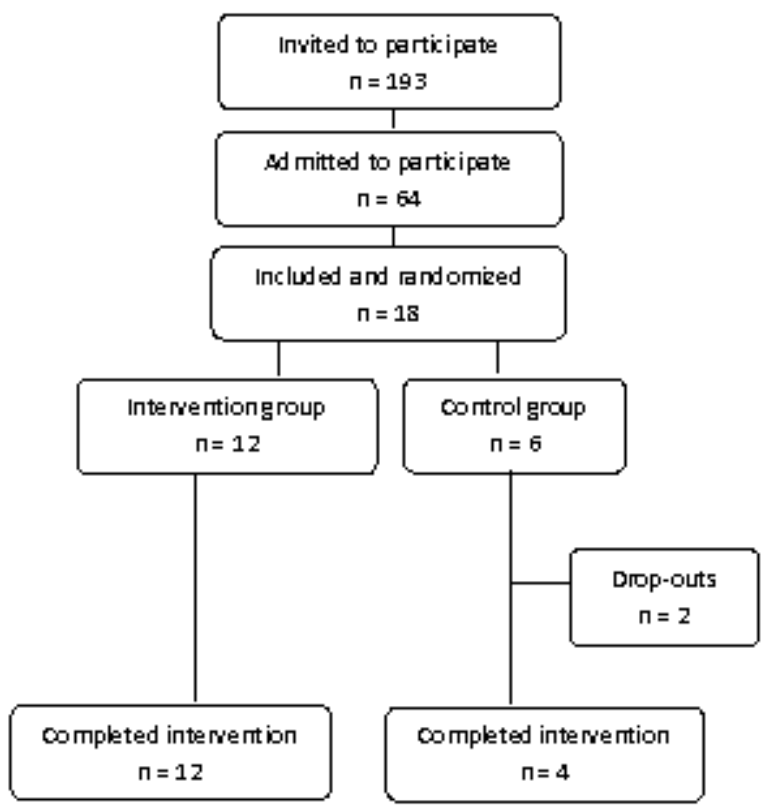

Figure 3. Recruitment of study patients. 
APPENDIX. Characteristics of the six tests chosen from the Cognitive Assessment Battery

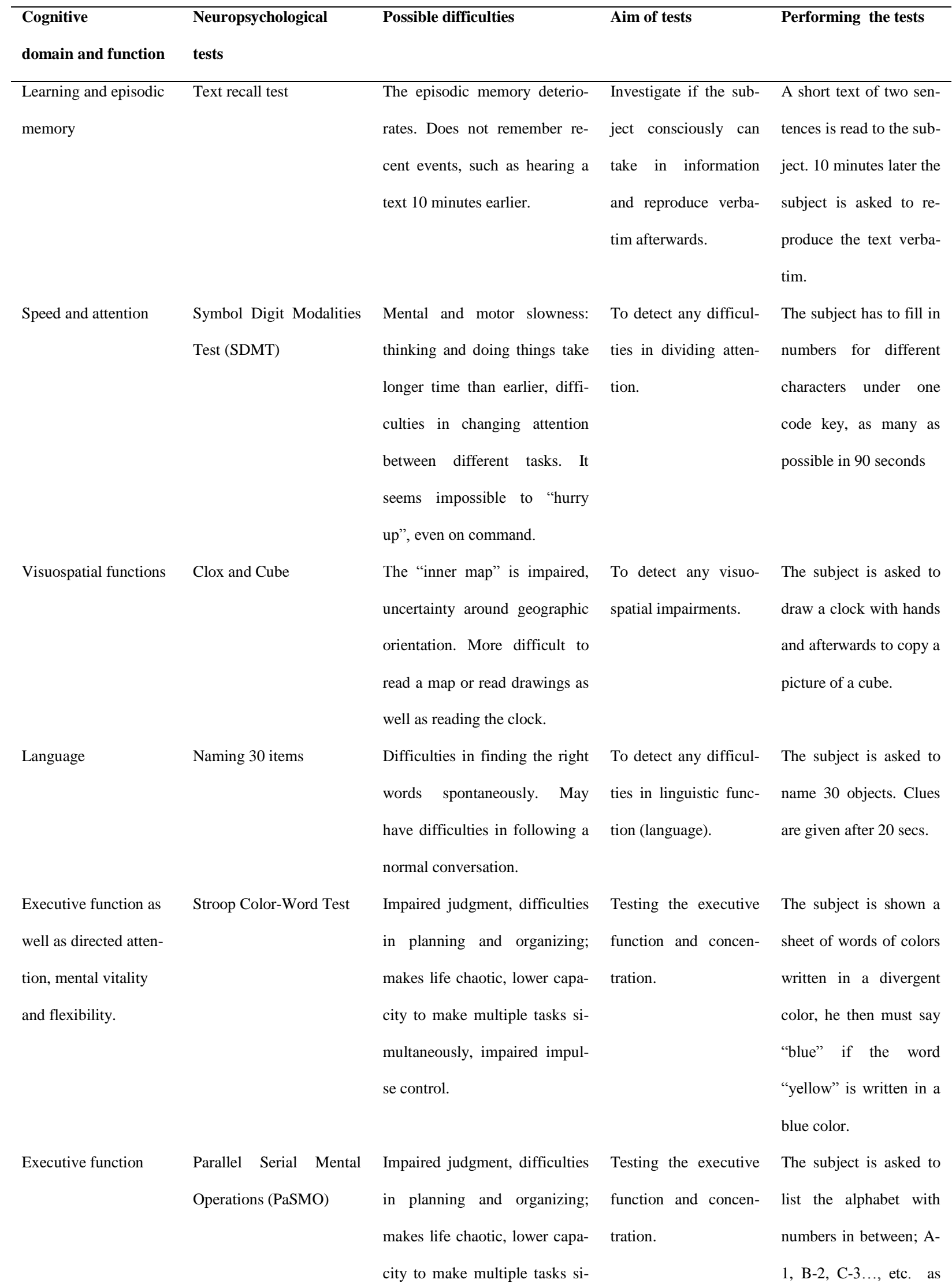


se control. 